\title{
Metal Oxides and Ultraviolet Light-based Photocatalytic Pretreatment of Biomass for Biogas Production and Lignin Oxidation
}

\author{
Muhammad Awais, ${ }^{\mathrm{a}, *}$, Muhammad Salman Mustafa, ${ }^{\mathrm{b}}$ Muhammad Asif Rasheed, \\ Farrukh Jamil, ${ }^{a}$ and Syed Muhammad Zaigham Abbas Naqvi ${ }^{c}$
}

\begin{abstract}
Lignocellulosics are abundant and readily available as the raw material for the production of biogas. However, the structure of this raw material needs to be modified to increase its digestibility during anaerobic fermentation. Various pretreatment methods that have been proposed in the past have been examined; however, the focus of the present study was to pretreat a wheat straw (WS) substrate using an advanced oxidation process (AOP) with a metal oxide photocatalyst combined with ultraviolet (UV) irradiation. Four different metal oxides were examined at $0,1,2,3$, and $4 \%$ dosages (w/w) coupled with UV irradiation for 0,60,120, and $180 \mathrm{~min}$. Experimental results revealed that among all metal oxide catalysts examined, only the 4\% CuO combined with 180 min UV irradiation caused the most lignin to be released from the WS. This resulted in the highest vanillic acid (VA) being produced $(4.32 \pm 0.15 \mathrm{mg} \mathrm{VA} / \mathrm{g} \mathrm{VS})$. This WS pretreatment also resulted in a biomethane potential (BMP) assay of $384 \pm 16 \mathrm{NmL} \mathrm{CH}_{4} / \mathrm{g}$ VS. The BMP assay results revealed a maximum $28 \%$ increase in biodegradability and a $57 \%$ increase in methane production. The use of either metal oxide catalysts or UV irradiation alone resulted in ineffective WS pretreatment.
\end{abstract}

Keywords: Photocatalysis; Wheat straw; Metal oxides; Lignin oxidation; UV light

Contact information: a: Department of Biosciences, COMSATS University Islamabad, Sahiwal Campus, Off GT road, 57000, Sahiwal, Pakistan; b: Department of Mechanical Engineering, COMSATS University Islamabad, Sahiwal Campus, Off GT road, 57000, Sahiwal, Pakistan; c: Collage of Mechanical and Electrical Engineering, Henan Agricultural University, Zhengzhou, 450002, China;

* Corresponding author: muhammad.awais@cuisahiwal.edu.pk

\section{INTRODUCTION}

There is much discussion on the use of renewable energy resources to replace fossil fuels that are more environmentally sustainable and carbon neutral. For these reasons, lignocellulosic biomasses represent a better raw material to produce biofuels to possibly replace non-renewable fossil fuels. However, there is a hindrance accompanying the use of this rich biomass, which is the close structural packing fibers of cellulose, hemicellulose, and lignin. The primary bottleneck involves the breakdown of the recalcitrant matrix of lignocellulosic constituents prior to biodegradation treatments (Akhtar et al. 2016). Different pretreatments have been developed that include chemical, biological, and physical methods. The main purpose of these methods is to alter and/or remove lignin and hemicelluloses, to decrease cellulose crystallinity, and to maximize enzymatic action by increasing the surface area of the substrate (Kumari and Singh 2018). Among the abovementioned pretreatments, most are accompanied by different barriers. Some of these include the need for high temperature and increased pressure, or the utilization of various 
compounds that yield noxious substances in the process of fermentation (Clark and Mackie 2007).

The oxidation of lignocellulosic biomass in the presence of a catalyst can represent a very favorable pretreatment method. These mild oxidation conditions can involve the use of various reaction pressures, temperatures, and $\mathrm{pH}$ values without introducing harmful substances into the oxidized sample. Several studies have focused on the oxidation of lignin and its subsequent conversion to valuable products (Sainsbury et al. 2013). Hence, a complex lignin polymer is converted to low molecular weight fragments that contain phenolic groups.

For lignin photocatalysis under mild conditions, advanced oxidation processes (AOP) can also be used as an alternate solution, in which photocatalysis driven redox reactions are used to decompose and subsequently oxidize lignin to products of economic interest (e.g., vanillic acid, $p$-coumaric acid, benzoic acid, vanillin, etc.) with vanillic acid as major product of oxidation (Ksibi 2003). A considerable amount of work has been done to produce low-cost, stable, practically feasible and efficient photocatalysts (Rawalekar and Mokari 2013). One of the most studied photocatalysts is titanium dioxide $\left(\mathrm{TiO}_{2}\right)$, which absorbs light in the form of rutile or anatase in the ultraviolet (UV) region, but still its photo-catalysis, stability, and band gap is variable if its composites are made with different metal oxides (Kazuhito et al. 2005). However, the light scattered by the rutile $\mathrm{TiO}_{2}$ is more than it absorbs; thus it is rarely used as a photocatalyst. This form of $\mathrm{TiO}_{2}$ is mainly used in paints and pigments. Anatase $\mathrm{TiO}_{2}$ is considered to be very active because of its surface chemistry and its higher conduction band energy (Hoffmann et al. 1995).

Titanium dioxide is generally considered as a highly effective catalyst for detoxifying organic contaminants contained in wastewater, when activated by ultraviolet (UV) light (Al-Dawery 2013). With emerging catalysis technologies, more potential candidates are introduced that can disrupt biomass bonding and increase the digestibility of lignocellulosic materials. In addition, the excitation of a photocatalyst with electromagnetic energy that is higher than its bandwidth is considered essential to the photo-oxidation process. Furthermore, many advantages have been reported with titanium dioxide $\left(\mathrm{TiO}_{2}\right)$, copper oxide $(\mathrm{CuO})$, and zinc oxide $(\mathrm{ZnO})$ photocatalysts; these advantages include low toxicity, improved solubility, low cost, high stability, ease of excitation, and ability to make thin layers on steel or glass (Kumar and Devi 2011). In the photo-oxidation process, water molecules are fragmented into radicals due to the photon energy absorbed by photocatalysts that form electron-hole pairs. The hydroxyl radical $\left(\mathrm{HO}^{\bullet}\right)$ formed in this process can completely demineralize various organic contaminants (e.g., organic acids, amines, and dyes) (Lacombe and Keller 2012).

Titanium dioxide and other metal oxides, such as $\mathrm{CuO}$, iron (III) oxide $\left(\mathrm{Fe}_{2} \mathrm{O}_{3}\right)$, and $\mathrm{ZnO}$, have been reported to act as photocatalysts. Titanium dioxide use in paints and dyes is well known, but it is also used in cosmetics and antimicrobial products due to its photocatalytic activity (Nations et al. 2011). The design of the present study is to explore the photocatalytic properties of various commercially available photocatalysts to disturb the complex structure of wheat straw (WS) and promote biogas production with improved feed stock digestibility. This study was also designed to complete further work based on an earlier investigation (Alvarado-Morales et al. 2017). Moreover, the current study aimed to identify a potentially more favorable catalyst for the photo-oxidation of lignin contained in the biomass substrate. 


\section{EXPERIMENTAL}

\section{Materials}

\section{Characteristics of inoculum and WS}

Inoculum was taken from a local biogas plant situated at the PMAS-Arid Agriculture University, Rawalpindi Pakistan, and was incubated at thermophilic conditions and degassed prior to experimental use. The inoculum was also subjected to various tests that resulted in total volatile fatty acids (TVFAs) $8.23,0.3 \pm 0.0 \mathrm{~g} / \mathrm{L}$, total solids (TS) 26.3 $\pm 2.1 \mathrm{~g} / \mathrm{L}$, and volatile solids (VS) $16.6 \pm 1.4 \mathrm{~g} / \mathrm{L}$. Among the VFAs, acetate was $0.15 \pm$ $0.0 \mathrm{~g} / \mathrm{L}$, whereas all other VFAs were at negligible concentration levels. Moreover, the ammoniacal nitrogen $\left(\mathrm{NH}_{4}-\mathrm{N}\right)$ and total Kjeldahl nitrogen were measured as $3.1 \pm 0.2 \mathrm{~g} / \mathrm{L}$ and $2.9 \pm 0.1 \mathrm{~g} / \mathrm{L}$, respectively.

The WS was collected from a local farm in the district of Sahiwal (Pakistan). The straw was dried, cut, and sieved into 3- to 4-cm segments using a CM1000 Cutting Mill (Laarmann Group, B.V., Roermond, Netherlands). The cut WS was stored in plastic bags at $4{ }^{\circ} \mathrm{C}$ until needed. The WS was also analyzed for its basic properties. The measured results were $93.1 \% \pm 1.2 \%$ TS and $87.4 \% \pm 1.6 \%$ VS (fresh samples). The Klason lignin was measured as $26.7 \% \pm 0.3 \%$ of TS, whereas cellulose and hemicelluloses were $43.3 \%$ $\pm 0.7 \%$ of TS and $29.6 \% \pm 0.6 \%$ of TS, respectively.

\section{Advanced oxidation process $(A O P)$ pretreatments}

The pretreatments were performed in accordance to the previous published method of Alvarado-Morales et al. (2017). Specifically, the samples were prepared by soaking 0.93 $\mathrm{g}$ of WS in $240 \mathrm{~mL}$ of water while continuously stirring at $200 \mathrm{rpm}$ to evenly distribute the solids. The slurry was placed $30 \mathrm{~cm}$ away from a UV-lamp (SUV-100P; UV Superstore, Inc., Winder, GA, USA)

The UV beams were collimated using a hollow tube (Fig. 1) to increase the efficacy of the pretreatments (Hansen et al. 2013). All the pretreatments were subject to an initial temperature of $25{ }^{\circ} \mathrm{C}$. Four different photocatalysts were obtained from Sigma Aldrich (Darmstadt, Germany). The four catalysts, $\mathrm{TiO}_{2}, \mathrm{CuO}, \mathrm{Fe}_{2} \mathrm{O}_{3}$, and $\mathrm{ZnO}$ were used to pretreat the WS at concentration dosages of $0,1,2,3$, or $4 \%$ (w/w on dry WS). The WS with photocatalyst was exposed to UV light for $0,60,120$, or $180 \mathrm{~min}$ for pretreatment. After the pretreatments, three fourths of the pretreated sample was subject to biomethane potential (BMP) experiments to evaluate methane production from the pretreated samples; the experiments were repeated three times. While the remaining one fourth of the pretreated sample was subject to further analysis via SEM and vanillic acid (VA) analysis to justify the pretreatment.

\section{BMP assay}

Biomethane potential assays were conducted on pretreated samples and controls using the protocol described by Angelidaki et al. (2009) at mesophilic conditions. The 327$\mathrm{mL} \pm 1 \mathrm{~mL}$ glass bottles, with $100 \mathrm{~mL}$ of working volume, were prepared for BMP assays, with $40 \%$ of inoculum and a $2 \mathrm{~g} \mathrm{VS} / \mathrm{L}$ organic loading rate (OLR).

Bacterial colonies usually form dense aggregations and are not evenly distributed if the bioreactors are not agitated. Hence, the bioreactors were manually shaken twice a day. Each reactor's accuracy was validated using a positive control with Avicel ${ }^{\circledR} \mathrm{PH}-101$ cellulose (Sigma Aldrich, Darmstadt, Germany). Glass bottles with $80 \mathrm{~mL}$ of inoculum and $120 \mathrm{~mL}$ of water were used to determine the residual methane of all samples. Furthermore, 
the glass bottles were flushed with nitrogen gas and sealed with rubber corks. Every BMP assay was repeated in triplicate to ensure the reproducibility of the measured results.

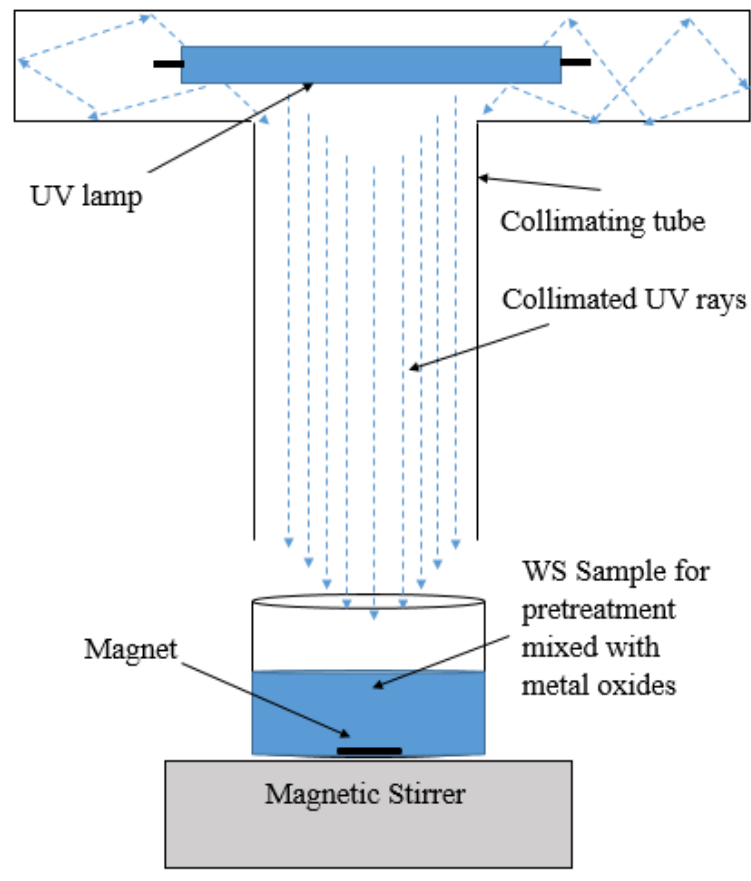

Fig. 1. Schematic of the pretreatment set-up used for UV irradiation of the WS samples with photocatalyst

\section{Methods}

The determinations of $\mathrm{NH}_{4}-\mathrm{N}$, total Kjeldahl nitrogen, $\mathrm{pH}$, VS, and TS were conducted according to standard protocols as described by the National Renewable Energy Laboratory (NREL) (Sluiter et al. 2011). A Fisher FE150 pH meter (Fisher Scientific, Hampton, NH, USA) was used to measure the $\mathrm{pH}$ of the samples. The VFAs analysis of the inoculum was performed using the protocol specified by Kougias et al. (2014) using an internal standard (4-methylvaleric acid). The procedure used a gas chromatograph (GC) with an auto-sampler (Kugelman and McCarty 1965). A Clarus 500 GC instrument (PerkinElmer, Waltham, MA, USA) was operated with a split/split-less injector. The methane contents from the BMP reactors were investigated using a (flame ionization detector (FID, Agilent Technologies, Waldbronn, Germany). The separation was completed using a glass capillary column with the dimensions of $3 \mathrm{~m} \times 6 \mathrm{~mm}$ and with an inner diameter of 2.5 $\mathrm{mm}$ (Restek, Bellefonte, PA, USA). The GC temperatures were $110^{\circ} \mathrm{C}$ and $160{ }^{\circ} \mathrm{C}$ for the injection and the detection ports, respectively. Klason lignin and carbohydrates were determined using NREL standard protocols (Sluiter et al. 2011).

Strong acid hydrolysis was followed by elemental analysis using a vario MACRO cube elemental analyzer (Elementar, Langenselbold, Hesse, Germany) to determine macroand micro-nutrients (e.g., trace metals) in the wheat straw (Awais et al. 2016). The determinations of elemental levels of carbon, hydrogen, nitrogen, oxygen, and sulphur, as well as $\mathrm{C} / \mathrm{N}$ ratio, were performed using a vario MACRO cube elemental analyzer (Elementar, Langenselbold, Hesse, Germany). All determinations were performed in triplicate to determine experimental error/variability. An UltiMate 3000 ultra-high performance liquid chromatograph (UHPLC; Thermo Fisher Scientific, Waltham, MA, 
USA) coupled with a Dionex UltiMate 3000 multiple wavelength detector (Thermo Fisher Scientific) was used to evaluate the products that arose from lignin oxidation. Separations with the UHPLC were completed using a BDS Hypersil C18 reverse phase column (4.6 $\mathrm{mm} \times 100 \mathrm{~mm}$ ) and $5 \mu \mathrm{m}$ particle size (Thermo Fisher Scientific, Waltham, MA, USA) equipped with a BDS Hypersil C18 guard column $(4 \mathrm{~mm} \times 10 \mathrm{~mm})$ and $5 \mu \mathrm{m}$ particle size (Thermo Fisher Scientific, Waltham, MA, USA). At a constant flow rate of $1 \mathrm{~mL} / \mathrm{min}$ in $0.3 \%(\mathrm{v} / \mathrm{v})$ acetic acid gradient, the separation was achieved. During the separation of contents, the compartment temperature was set at $30{ }^{\circ} \mathrm{C}$, and injection volume was $20 \mu \mathrm{L}$. The surface analysis of the nanocomposites and wheat straw after pretreatment were performed using a thermionic tungsten gun equipped with a scanning electron microscope (SEM-FEI Inspect S; FEI Co., Hillsboro, OR, USA) fitted with large field detectors operating under high vacuum mode.

\section{Statistical analysis}

Descriptive statistical measures, means, and standard deviations of all the raw data sets (treated and untreated samples) were analyzed using Microsoft Excel software (2007 version, Microsoft Corp., Redmond, WA, USA). A one-way analysis of variance (ANOVA) was used to compare the means of the data sets using a $\mathrm{p}<0.05$ significance level.

\section{RESULTS AND DISCUSSION}

\section{Lignin Oxidation}

Lignin oxidation was performed to justify the ability of metal oxides and UV light to cause pretreatment of wheat straw. The control treatments resulted in non-significant ( $\mathrm{p}$ $<0.05$ ) amounts of produced VA. With a consistent increase in monocatalyst $\mathrm{TiO}_{2}$ concentration, a non-significant increase in lignin oxidation was also observed. The control treatment containing 1, 2, 3, and $4 \% \mathrm{TiO}_{2}$ was not exposed to the UV light; therefore no significant change was observed in VA concentration $(0.12,0.15,0.14,0.1$, and $0.16 \mathrm{mg}$ $\mathrm{VA} / \mathrm{g}$ VS). Another set of experiments was designed to observe the VA production from lignin oxidization under UV irradiation (60 min) using various concentrations of $\mathrm{TiO}_{2}$ catalyst $(0$ to $4 \%)$. It was concluded that with increasing catalyst concentration and UV exposure, pretreatment extent was increased. When the WS was pretreated with 120 min of UV irradiation with $4 \% \mathrm{TiO}_{2}$ catalyst, the VA production was $2.2 \pm 0.1 \mathrm{mg} \mathrm{VA} / \mathrm{g} \mathrm{VS}$, whereas with $0 \% \mathrm{TiO}_{2}$ the $\mathrm{VA}$ production was only $0.16 \pm 0.0 \mathrm{mg} \mathrm{VA} / \mathrm{g} \mathrm{VS}$. The maximum VA production of $2.7 \pm 0.1 \mathrm{mg} \mathrm{VA} / \mathrm{g} \mathrm{VS}$ was observed when $4 \% \mathrm{TiO}_{2}$ and $180 \mathrm{~min}$ of UV irradiation were used. Earlier results revealed that increasing the UV light exposure time increased lignin oxidation, which was presumably caused by the generation of more hydroxyl radicals (Portjanskaja et al. 2006). The observed increased VA production corresponded to morphological changes observed with the solid surfaces that were caused by $4 \% \mathrm{TiO}_{2}$ and 180 min of UV irradiation pretreatment (versus the untreated control) (Fig. 3). A second set of experiments involved pretreating the WS with $\mathrm{ZnO}$ catalyst at various conditions as described earlier. The control treatment with no UV exposure resulted in insignificant amounts of VA production $(\mathrm{p}<0.05)$. Oxidation of lignin increased as the UV exposure time increased when the $\mathrm{ZnO}$ catalyst was used. When $0 \% \mathrm{ZnO}$ catalyst was used, the VA yields were insignificant $(\mathrm{p}<0.05)$. 
(a)

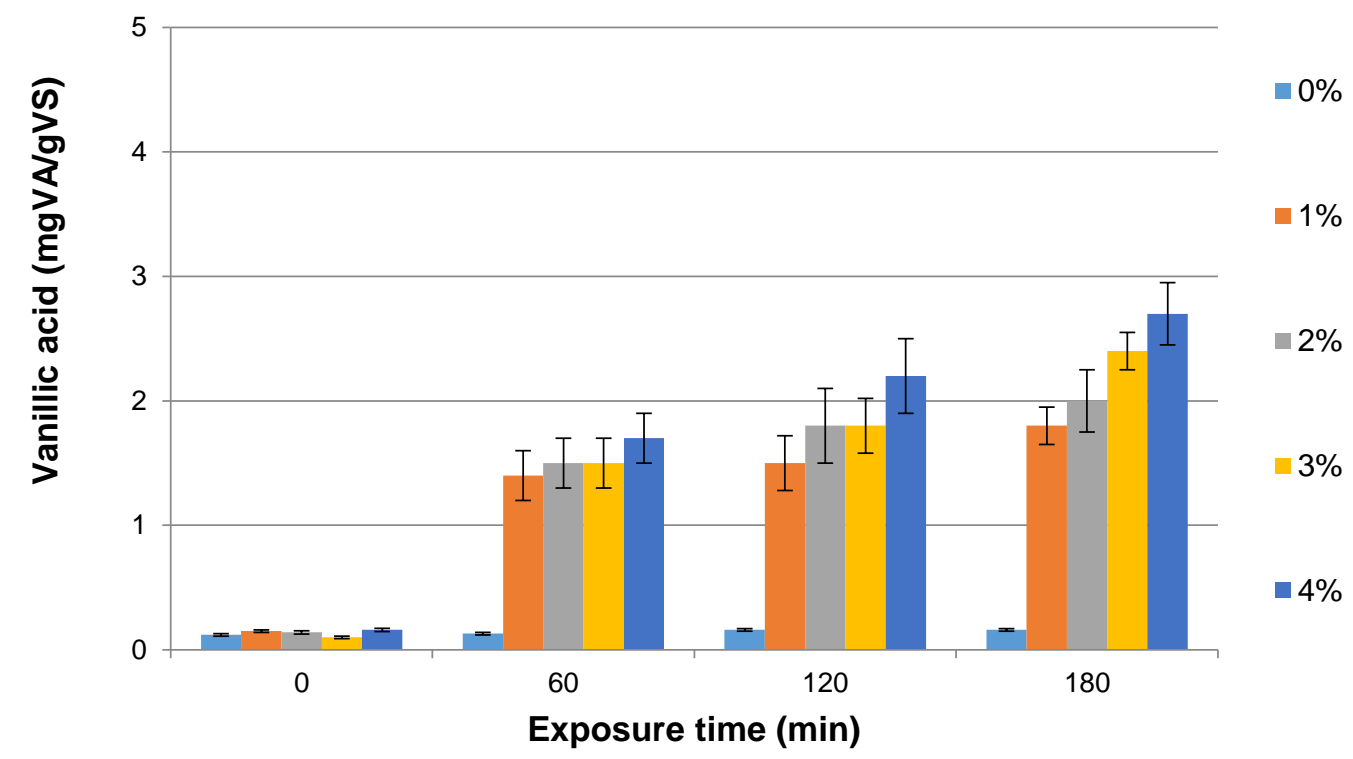

(b)

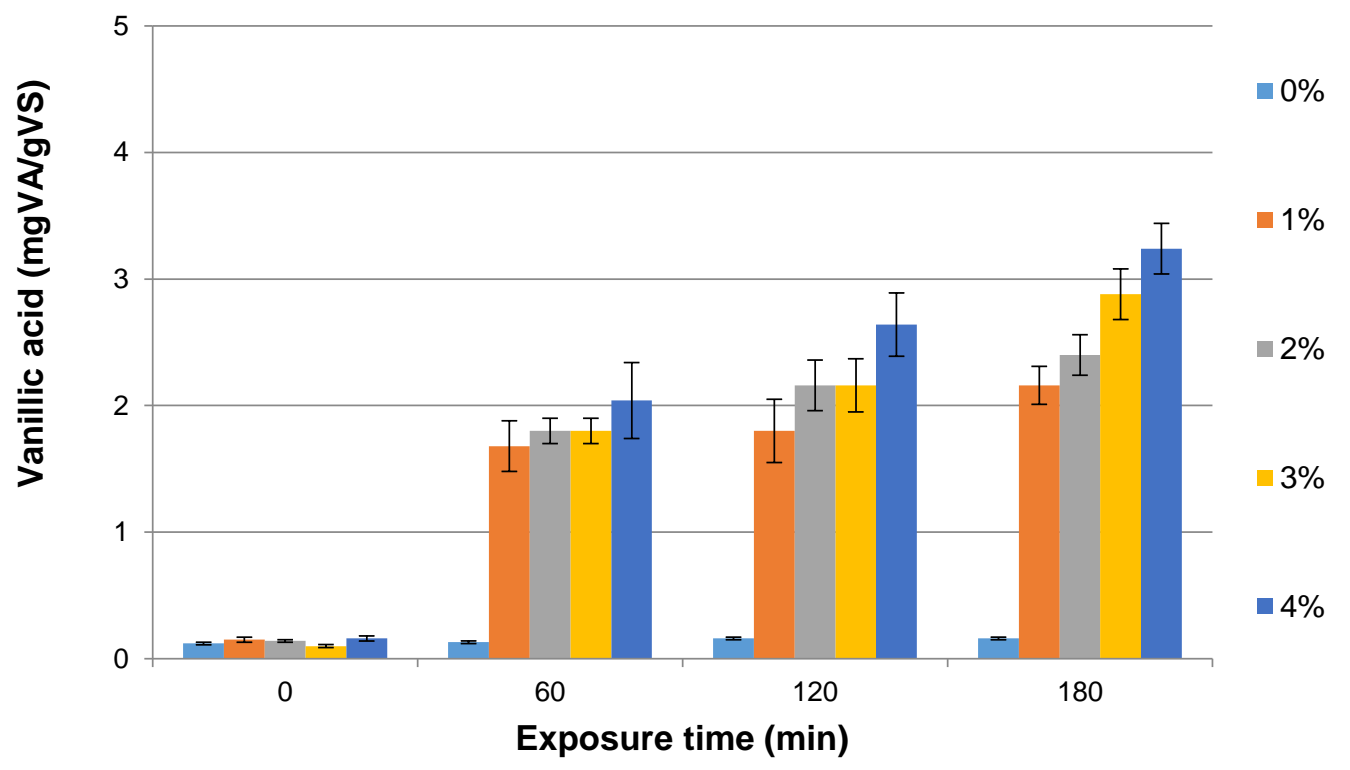


(c)

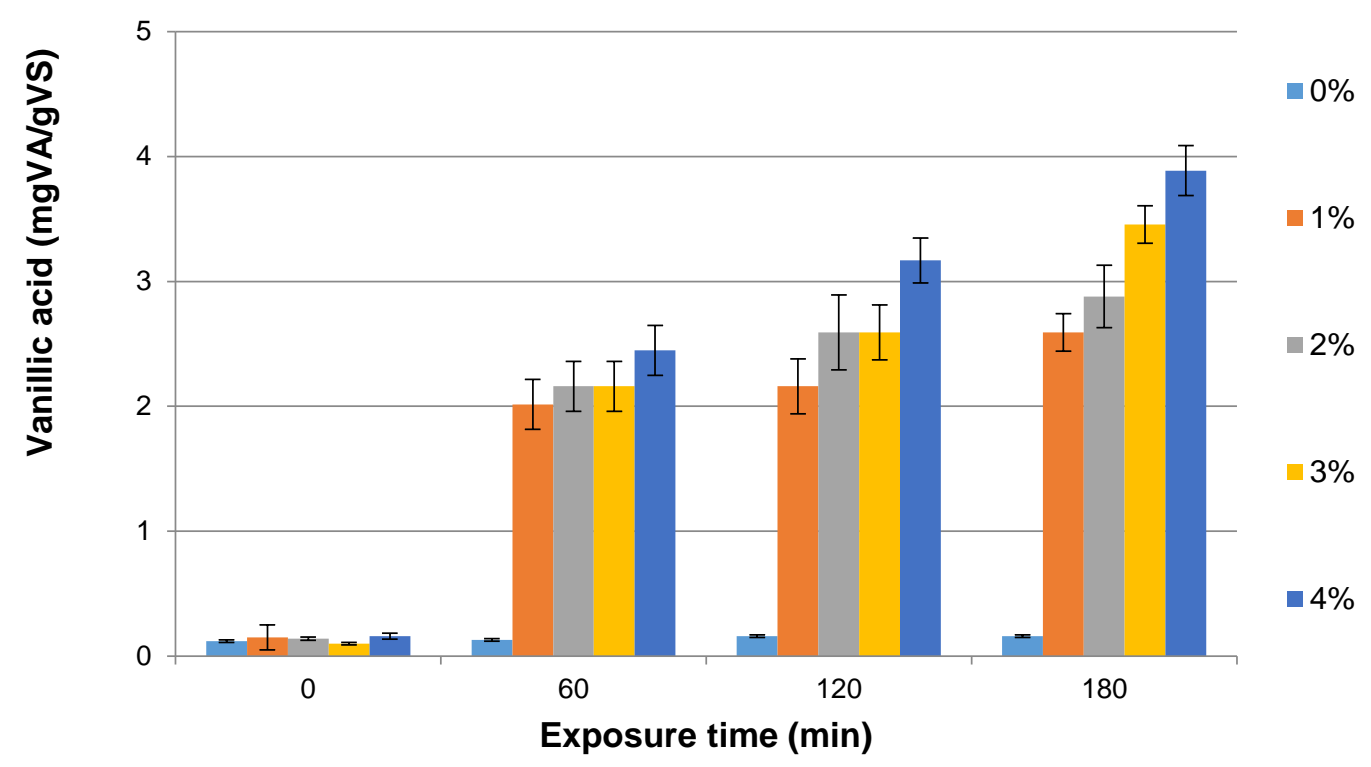

(d)

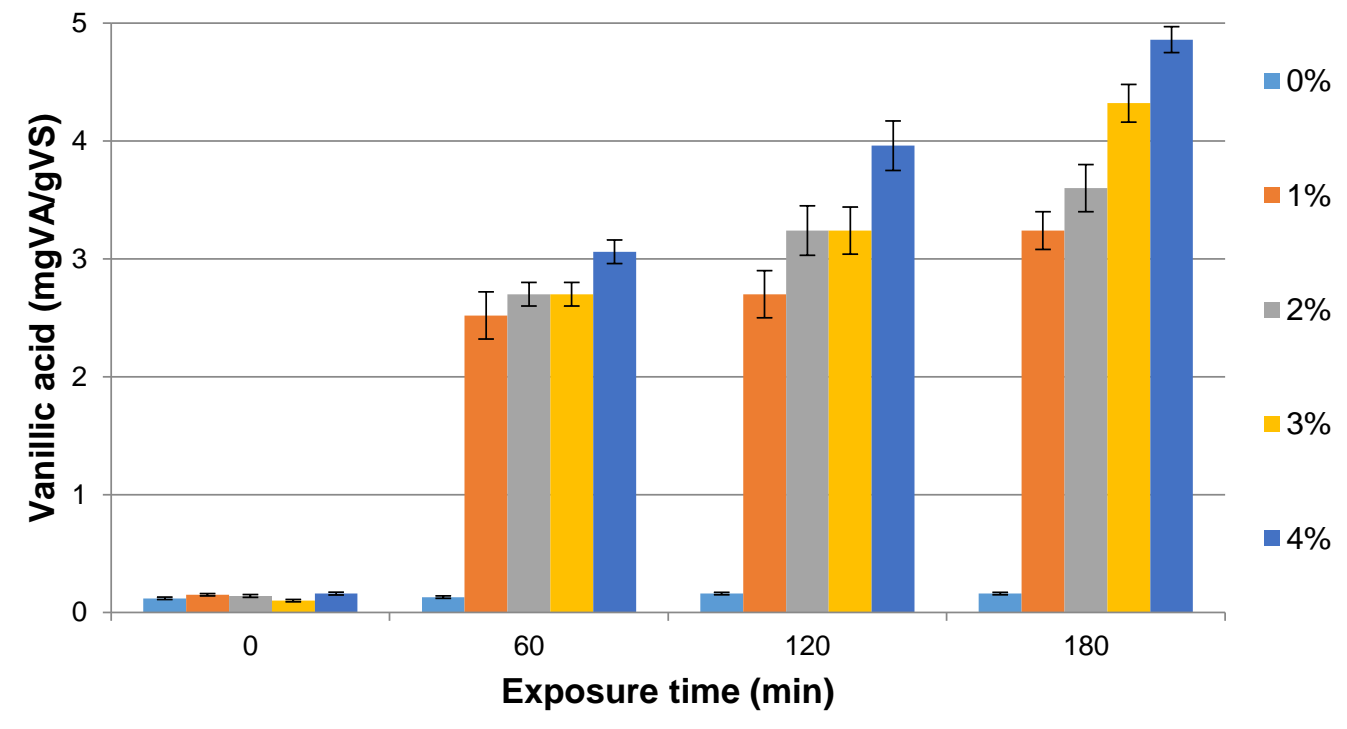

Fig. 2. Comparisons of different pretreatment conditions using various photocatalysts on VA production from lignin oxidation based on the total VS (a) $\mathrm{TiO}_{2}$ Pretreatment (b) ZnO Pretreatment (c) $\mathrm{Fe}_{2} \mathrm{O}_{3}$ Pretreatment (d) $\mathrm{CuO}$ Pretreatment 


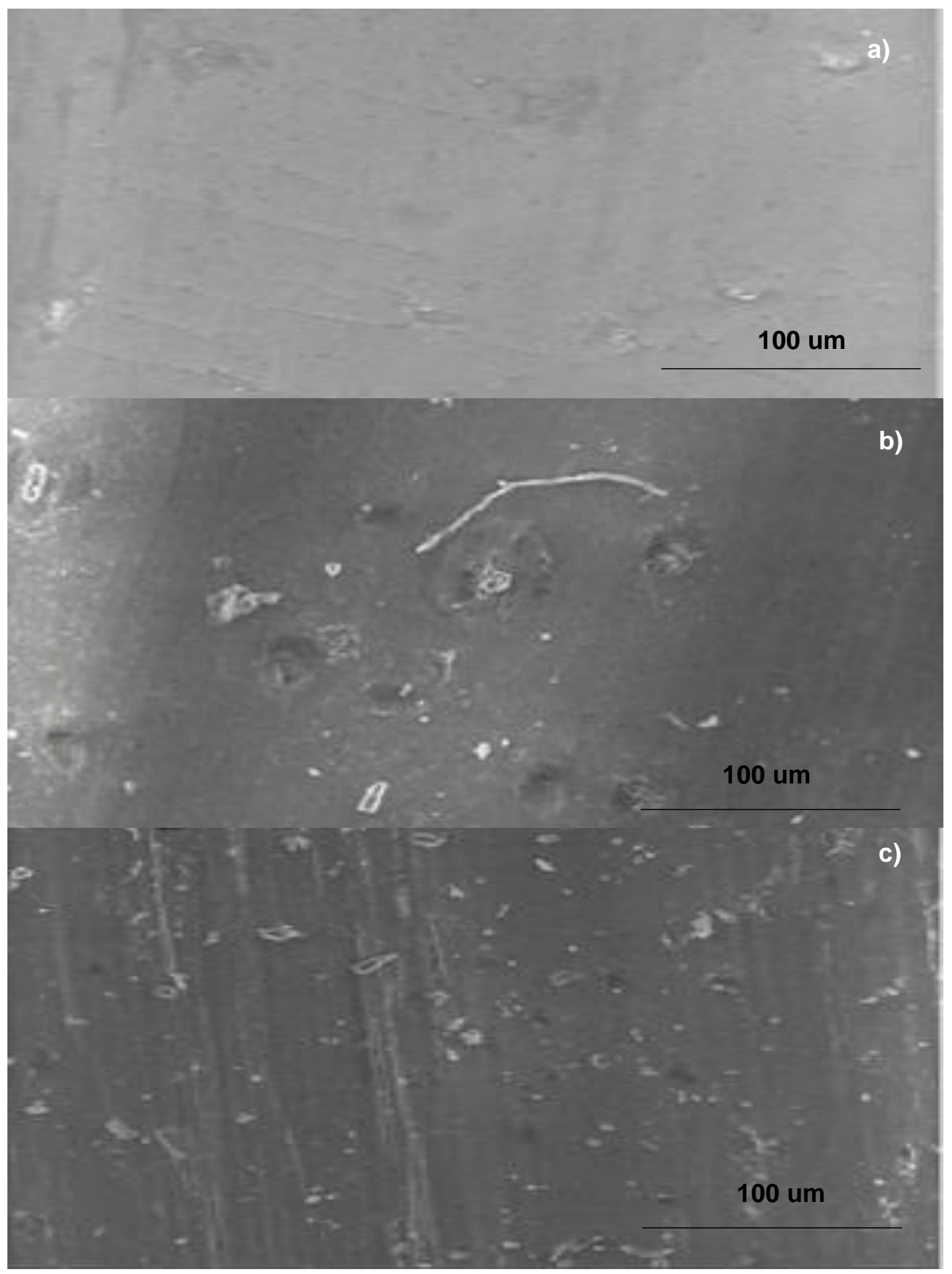




\section{bioresources.com}

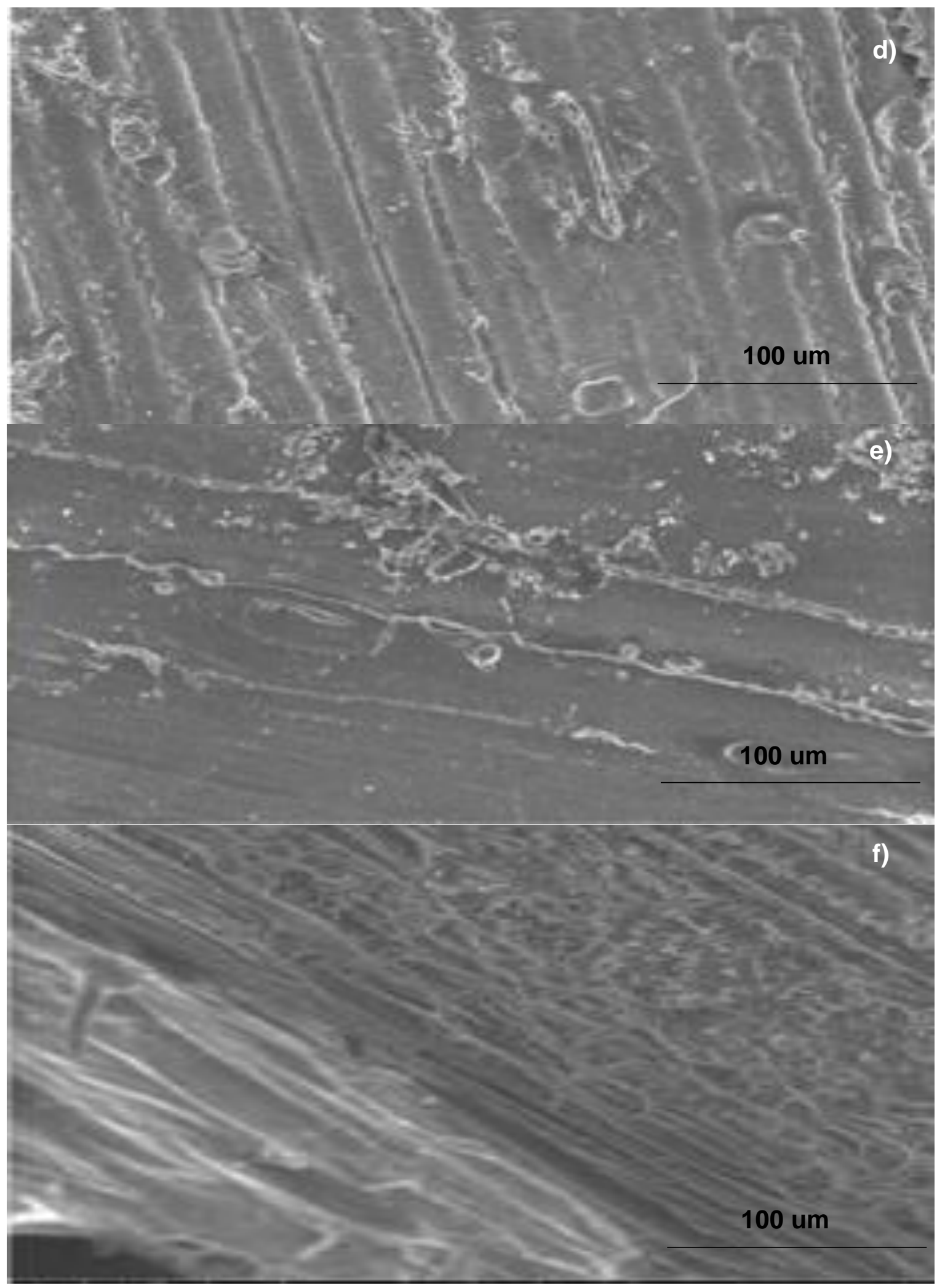

Fig. 3. SEM images of WS: (a) double negative control; (b) only 180 min UV irradiation (no catalyst); (c) pretreated with $4 \% \mathrm{TiO}_{2}$ and 180 min UV irradiation; (d) pretreated with $4 \% \mathrm{ZnO}$ and 180 min UV irradiation; (e) pretreated with $4 \% \mathrm{Fe}_{2} \mathrm{O}_{3}$ and 180 min UV irradiation; and (f) pretreated with $4 \% \mathrm{CuO}$ and 180 min UV irradiation 
Significantly higher concentrations of VA $(3.24 \pm 01 \mathrm{mg}$ VA/g VS) were detected when $4 \% \mathrm{ZnO}$ catalyst and $180 \mathrm{~min}$ of UV irradiation time was used. This trend was similar to the experiments conducted with the $\mathrm{TiO}_{2}$ catalyst, but the $\mathrm{ZnO}$ catalyst had higher VA production versus the $\mathrm{TiO}_{2}$ catalyst. The SEM analysis of the $\mathrm{ZnO}$-pretreated sample also offered more lignin release from biomass compared to $\mathrm{TiO}_{2}$ alone, so the escape of lignin from biomass enhanced the surface area for enzymatic degradation.

The $\mathrm{Fe}_{2} \mathrm{O}_{3}$ catalyst was used at various concentrations and UV exposure times to check the catalyst's potential to modify the WS surfaces. In the negative controls, the VA production was insignificant and revealed the legitimacy of the pretreatments as the UV and catalyst separately posed no significant effect on VA production. The trends showed increased VA production with increased UV exposure times and $\mathrm{Fe}_{2} \mathrm{O}_{3}$ catalyst concentration. More specifically, the $4 \% \mathrm{Fe}_{2} \mathrm{O}_{3}$ catalyst yielded a maximum $3.89 \pm 0.12$ $\mathrm{mg} \mathrm{VA} / \mathrm{g}$ VS after $180 \mathrm{~min}$ of UV exposure (Fig. 2c). These results were also observed in the SEM images of the modified WS surfaces when $\mathrm{Fe}_{2} \mathrm{O}_{3}$ was used in place of either $\mathrm{ZnO}$ or $\mathrm{TiO}_{2}$. The more extensive modifications to surfaces when $\mathrm{Fe}_{2} \mathrm{O}_{3}$ catalyst is used are presumed to cause more lignin to escape from the WS (Fig. 3) than with $\mathrm{ZnO}$ or $\mathrm{TiO}_{2}$; thus, it allowed for further lignin oxidation (i.e., VA production).

To speed up the reportedly slow and incomplete process of lignin oxidation, as reported by Deublein and Steinhauser (2011), CuO was examined in this study in conjunction with UV exposure to develop a more potent AOP pretreatment for WS. Using $\mathrm{CuO}$ catalyst with UV radiation resulted in a more extensive pretreatment of the WS when compared to all other UV photocatalysts examined in this study. The SEM images revealed that lignin fragments could diffuse more readily when $\mathrm{CuO}$ was used as the catalyst. The comparisons of the SEM images of Fig. 3 illustrated that $\mathrm{CuO}$ extensively modified the WS surfaces and loosened more of the bound fibers versus the other metal oxide catalysts at same conditions. This trend also highly affected the biodegradability of wheat straw and a treatment of $180 \mathrm{~min}$ of UV exposure with $4 \% \mathrm{CuO}$ resulted in $4.32 \pm 0.15 \mathrm{mg} \mathrm{VA} / \mathrm{g}$ VS (Fig. 2d). This VA production confirmed that $4 \% \mathrm{CuO}$ and $\mathrm{UV}$ exposure for $180 \mathrm{~min}$ resulted in the highest pretreatment and lignin oxidation afterwards, among all the pretreatments. The general trends indicated that lignin oxidization increased when the $\mathrm{CuO}$ catalyst concentration increased and when the UV irradiation time increased. Moreover, separately, $\mathrm{CuO}$ and UV light were not associated with any lignin oxidation, as the results of separate analysis showed insignificant differences (Fig. 2d).

\section{BMP Assay Results with WS Pretreated with Various AOPs}

The WS from the various AOP pretreatments was subjected to anaerobic digestion to produce biomethane. The pretreatment's effect of and validation of lignin oxidation were also determined by subjecting all the pretreatments to biomethane potential assays. The only $\mathrm{TiO}_{2}$-pretreated WS was also subjected to BMP assays. A control treatment (i.e., no photocatalyst and 0 min UV irradiation) was conducted with the WS. The biogas production from the WS control was $240 \mathrm{NmL} \mathrm{CH}_{4} / \mathrm{g}$ VS (standardized/normalized volumetric flow rate). The $\mathrm{TiO}_{2}$ catalyst was increased in $\Delta 1 \%$ increments, and the pretreatments were completed without UV irradiation $(0 \mathrm{~min})$. The amount of methane production was insignificant when compared to the control treatment $(\mathrm{p}<0.05)$ (Fig 4a). Generally, it can be observed that $\mathrm{TiO}_{2}$ catalyst alone does not significantly augment methane production (Alvarado-Morales et al. 2017). Using the combination of $4 \% \mathrm{TiO}_{2}$ and $180 \mathrm{~min}$ of UV irradiation yielded $2.7 \pm 0.1 \mathrm{mg} \mathrm{VA} / \mathrm{g} \mathrm{VS}$ and $333 \pm 15 \mathrm{NmL} \mathrm{CH} / \mathrm{g}$ VS (i.e., 33\% increase over control). 
BMP Assay Results with $\mathrm{TiO}_{2}$-pretreated WS

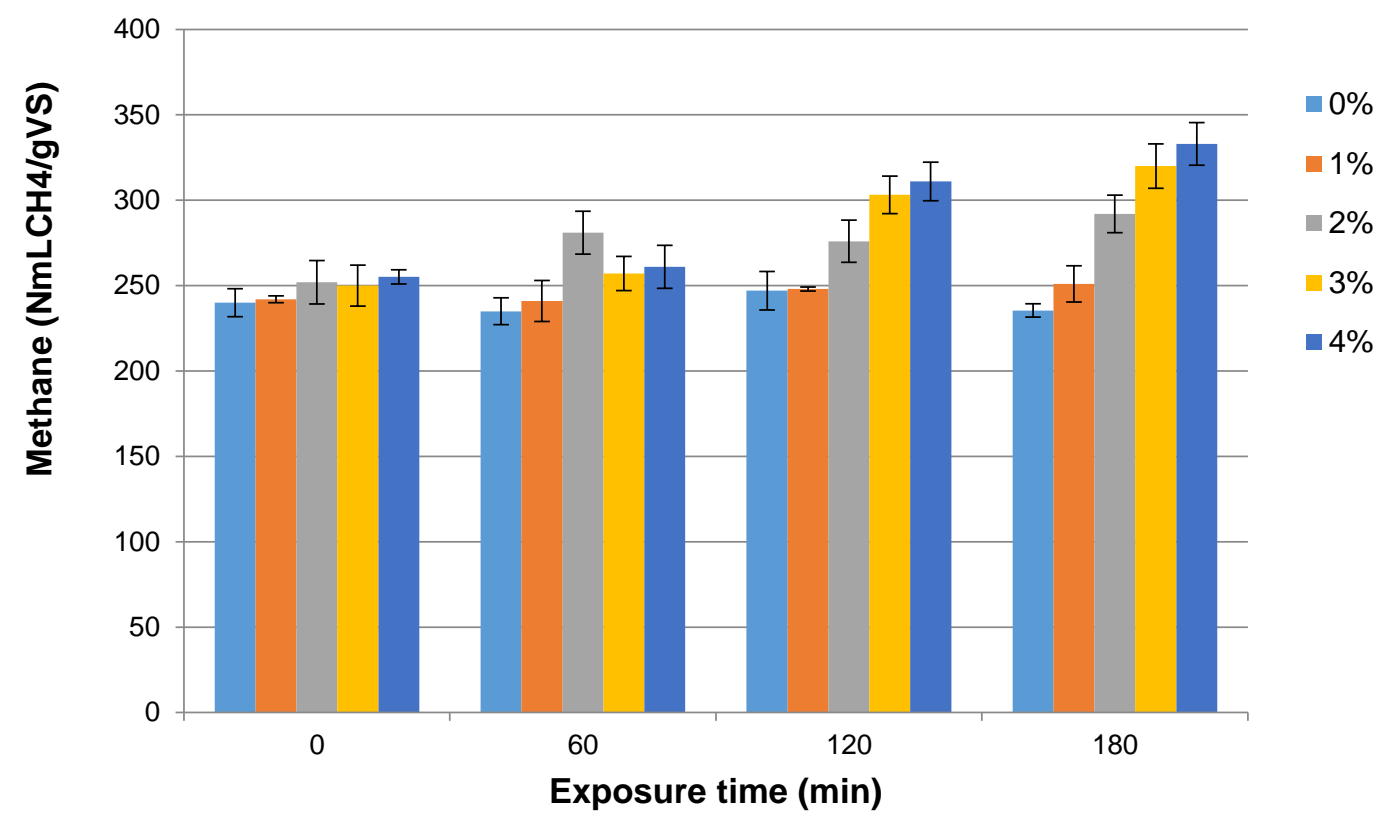

BMP Assay Results with ZnO-pretreated WS

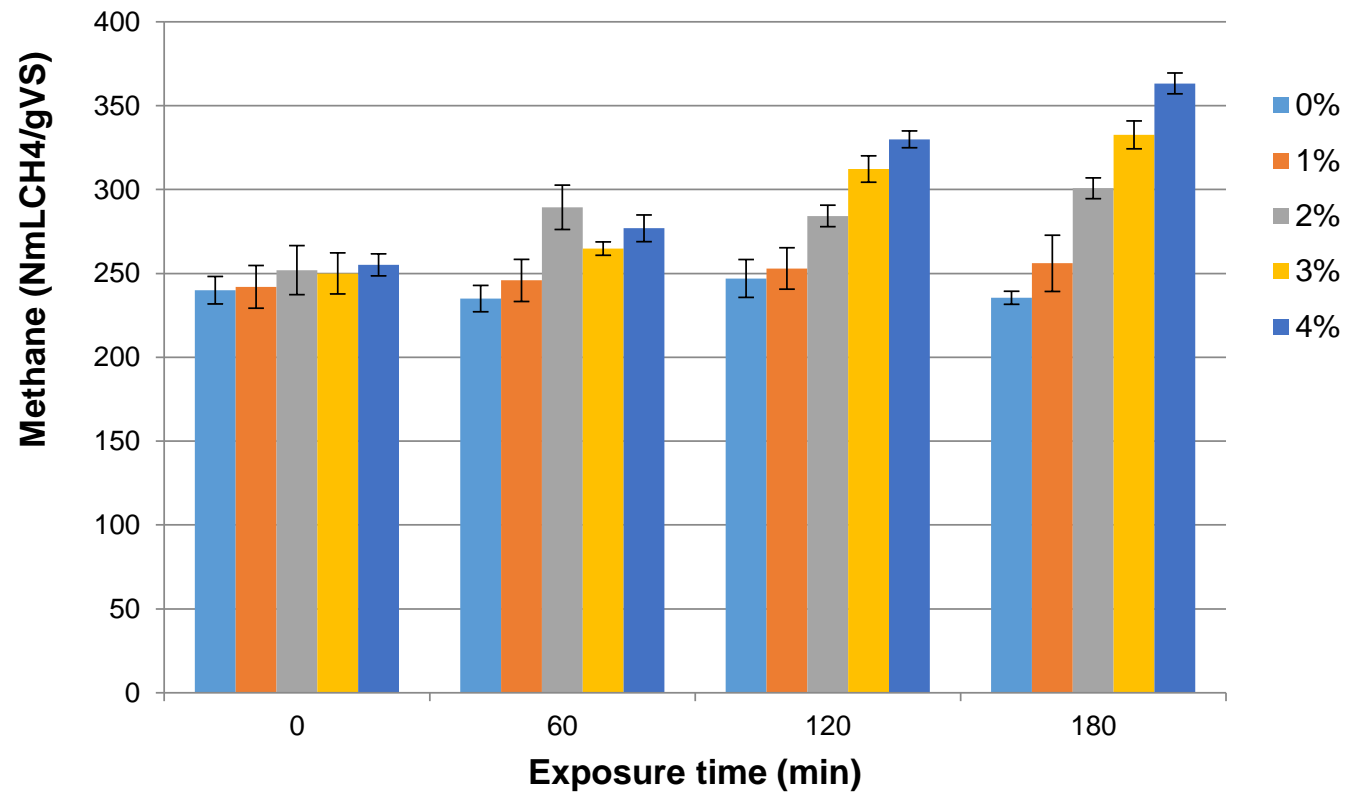


BMP Assay Results with $\mathrm{Fe}_{2} \mathrm{O}_{3}$-pretreated WS

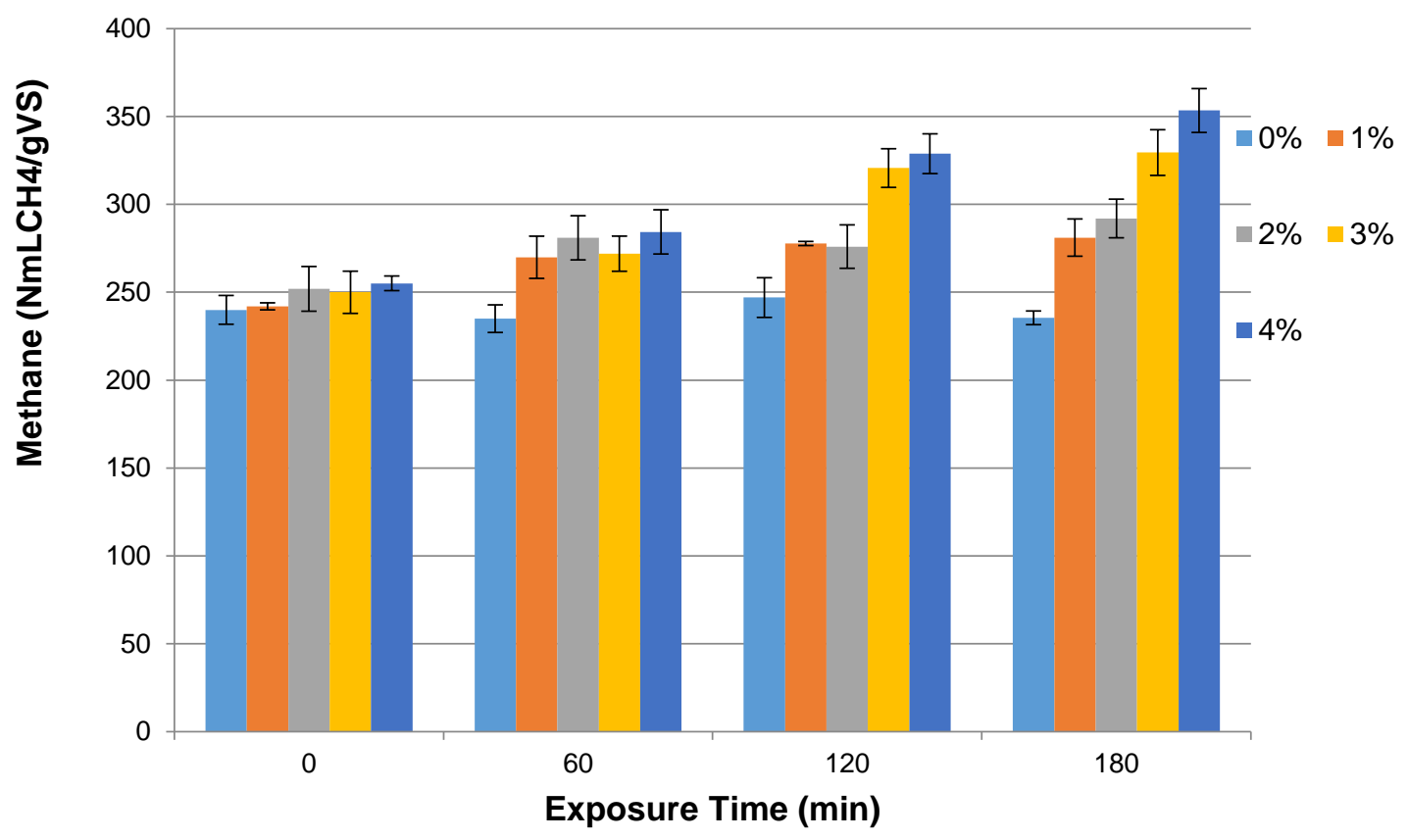

BMP Assay Results with CuO-pretreated WS

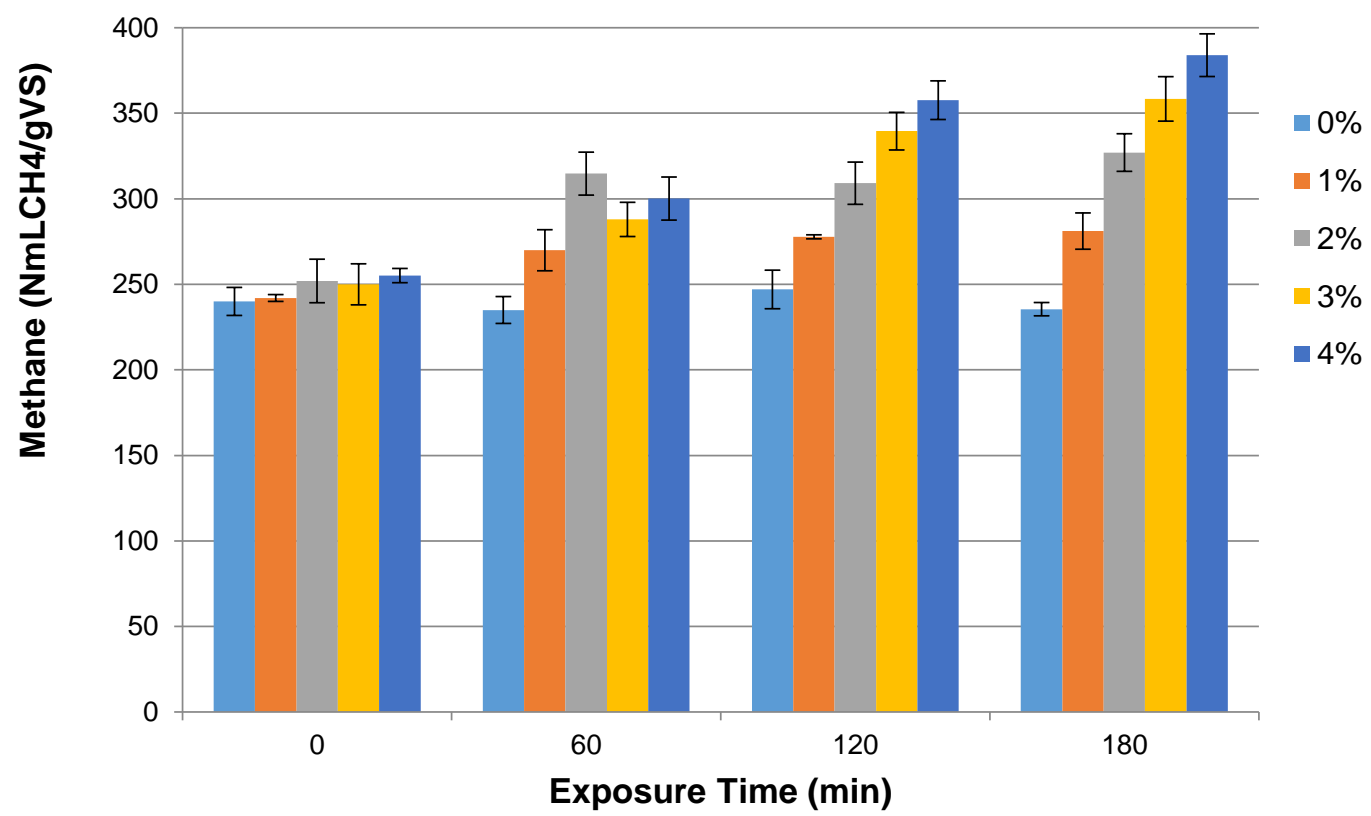

Fig. 4. Methane production during BMP assays with WS substrate treated with various pretreatment conditions and photocatalysts

The pretreated WS with $4 \% \mathrm{TiO}_{2}$ and 180 min of UV irradiation was observed to have more pits and furrows on its surface versus the untreated WS sample. Moreover, Carrere et al. (2016) indicated that the goals of biomass pretreatment are to remove lignin, reduce cellulose crystallinity, and increase substrate surface area for enzymes to interact. 
These observations established that increasing lignin escape and the development of pits on the WS surface increased the digestibility of WS under BMP assay.

In this section, $\mathrm{ZnO}$ was applied to increase the efficiency of lignin oxidation. No appreciable changes were observed in the control treatments with $\mathrm{ZnO}$ when compared to control treatments with $\mathrm{TiO}_{2}$. Methane production increased when the UV irradiation time increased for the various catalyst dosage levels. The production increased from $246 \pm 12$ $\mathrm{NmL} \mathrm{CH}_{4} / \mathrm{g}$ VS using 60 min UV irradiation and $1 \% \mathrm{ZnO}$ to a maximum of $353 \pm 17 \mathrm{NmL}$ $\mathrm{CH}_{4} / \mathrm{g}$ VS (i.e., $41 \%$ increase) using $4 \% \mathrm{ZnO}$ for $180 \mathrm{~min} \mathrm{UV}$ irradiation (Fig. 4b). The SEM analysis of the maximum pretreated sample revealed that the development of pits and escape of lignin were greater compared to the untreated and $\mathrm{TiO}_{2}$-pretreated WS under the same conditions. This can be explained by the fact that a photocatalyst offering more surface disruption alongside a pretreatment usually produces more hydroxyl radicals $\left(\mathrm{HO}^{\bullet}\right)$, superoxide radical anions $\left(\mathrm{O}_{2}{ }^{\bullet-}\right)$, and free holes on the surface of the substrate $(\mathrm{Ma}$ et al. 2008).

$\mathrm{Fe}_{2} \mathrm{O}_{3}$ was also utilized at various conditions to evaluate its possible effect on lignin oxidation and ability to offer pretreatment of WS. The ability of this catalyst to augment methane production without UV irradiation was negligible versus the control sets. Only $240 \pm 10 \mathrm{~mL} \mathrm{CH}_{4} / \mathrm{g}$ VS of methane was produced when there was no catalyst and no UV irradiation used (i.e., double negative control). The UV light alone could only produce nonsignificant ( $\mathrm{p}>0.05$ ) results for methane production $(235,247$, and $235 \mathrm{NmL} \mathrm{CH} 4 \mathrm{~g}$ VS after 60,120, and 180 min respectively). The highest amount of methane produced was after 180 min UV irradiation with the $4 \% \mathrm{Fe}_{2} \mathrm{O}_{3}$ catalyst (i.e., $363 \pm 14 \mathrm{NmL} \mathrm{CH}_{4} / \mathrm{g} \mathrm{VS}$; $48 \%$ increase), whereas the production was somewhat lower after 120 min UV irradiation (i.e., $339 \pm 16 \mathrm{NmL} \mathrm{CH}_{4} / \mathrm{g} \mathrm{VS}$ ).

A major difference was observed when both the time of UV exposure was increased and the amount of $\mathrm{Fe}_{2} \mathrm{O}_{3}$ catalyst applied. This reflected the good optical properties of $\mathrm{Fe}_{2} \mathrm{O}_{3}$ compared to $\mathrm{TiO}_{2}$ and $\mathrm{ZnO}$. More electrons are released from $\mathrm{Fe}_{2} \mathrm{O}_{3}$ during the oxidation process compared to $\mathrm{TiO}_{2}$ or $\mathrm{ZnO}$, which may create more free radicals to oxidize the biomass substrate (Wong et al. 2016). The SEM comparisons and VA analyses confirmed that more of the WS surface was modified using $\mathrm{Fe}_{2} \mathrm{O}_{3}$ catalyst with UV exposure when compared to either $\mathrm{TiO}_{2}$ or $\mathrm{ZnO}$ used with $\mathrm{UV}$ irradiation. This resulted in more lignin being released to be further oxidized into VA. It is well known that the fraction of lignin that escapes via photocatalysis is oxidized to various aromatic organic compounds (Li et al. 2016).

The WS pretreatment with $4 \% \mathrm{CuO}$ and 180 min UV irradiation resulted in a BMP assay of $384 \pm 16 \mathrm{NmL} \mathrm{CH}_{4} / \mathrm{g}$ VS (i.e., 57\% increase). This was the highest amount of methane observed for all the pretreatments examined in this study. These conditions also resulted in the highest values of VA production (i.e., $4.32 \pm 0.15 \mathrm{mg} \mathrm{VA} / \mathrm{g} \mathrm{VS}$ ) (Fig. 4d), as well as the most modifications to the WS surface (Fig. 3f). More modifications to the WS surface resulted in more lignin released from the substrate that could be further oxidized into VA. Kang and Kim (2012) reported that lignin oxidation results in the formation of VA, ferulic acid, and other VFAs that may be converted into VA during longer periods of UV irradiation. The general trend observed for all metal oxide photocatalysts was that production increased when the concentration of catalyst and the UV irradiation time were both increased. Hence, the results indicated that either UV exposure or metal oxide catalyst alone were not able to produce a high amount of methane. In all the experimental sets, only pretreatments using $4 \%$ catalyst and $180 \mathrm{~min}$ UV irradiation produced the highest methane yields. The process of the pretreatment used indicates the 
input of electrical energy, fresh water and feedstock. But the final products such as vanillic acid, methane and bio fertilizer from anaerobic digester can make this process industrially feasible.

\section{CONCLUSIONS}

1. The overall results observed from this study revealed that $\mathrm{CuO}$ was the most effective UV photocatalyst tested for the pretreatment of WS to release more lignin.

2. The maximum value of VA produced during this study was $4.32 \pm 0.15 \mathrm{mg} \mathrm{VA} / \mathrm{g} \mathrm{VS}$ and the methane production was $384 \pm 16 \mathrm{NmL} \mathrm{CH}_{4} / \mathrm{g}$ VS. The BMP assay results revealed a maximum $28 \%$ increase in biodegradability and a $57 \%$ increase in methane production.

3. The use of either a metal oxide catalyst or UV irradiation alone resulted in ineffective WS pretreatment.

4. The products of lignin oxidation, such as VA that is used as vanilla flavoring agent (Sinha et al. 2008), could be further utilized in the food industry as flavor if it could be produced in bulk.

5. The current study demonstrated a sustainable and a non-toxic pretreatment method for preparing biomass, such as WS, for further processing into bioproducts.

\section{ACKNOWLEDGMENTS}

The authors express their gratefulness to the Higher Education Commission (HEC) of Pakistan and the COMSATS University Islamabad for providing the funding and basic facilities to conduct this research.

\section{REFERENCES CITED}

Akhtar, N., Gupta, K., Goyal, D., and Goyal, A. (2016). "Recent advances in pretreatment technologies for efficient hydrolysis of lignocellulosic biomass," Environ. Prog. Sustain Energy. 35, 489-511. DOI: 10.1002/ep. 12257

Al-Dawery, S. K. (2013). "Photo-catalyst degradation of tartrazine compound in wastewater using $\mathrm{TiO}_{2}$ and UV light," Journal of Engineering Science and Technology 8(6), 683-691. DOI: 10.1080/19443994.2015.1025853

Alvarado-Morales, M., Tsapekos, P., Awais, M., Gulfraz, M., and Angelidaki, I. (2017). " $\mathrm{TiO}_{2} / \mathrm{UV}$ based photocatalytic pretreatment of wheat straw for biogas production," Anaerobe 46, 155-161. DOI: 10.1016/j.anaerobe.2016.11.002

Angelidaki, I., Alves, M., Bolzonella, D., Borzacconi, L., Campos, J. L., Guwy, A. J., Kalyuzhnyi, S., Jenicek, P., and Van Lier, J. B. (2009). "Defining the biomethane potential (BMP) of solid organic wastes and energy crops: A proposed protocol for batch assays," Water Science \& Technology 59(5), 927-934. DOI:

10.2166/wst.2009.040

Awais, M., Alvarado-Morales, M., Tsapekos, P., Gulfraz, M., and Angelidaki, I. (2016). 
"Methane production and kinetic modeling for co-digestion of manure with lignocellulosic residues," Energy \& Fuels 30(12), 10516-10523. DOI: 10.1021/acs.energyfuels.6b02105

Carrere, H., Antonopoulou, G., Affes, R., Passos, F., Battimelli, A., Lyberatos, G., and Ferrer, I. (2016). "Review of feedstock pretreatment strategies for improved anaerobic digestion: From lab-scale research to full-scale application," Bioresource Technology 199, 386-397. DOI: 10.1016/j.biortech.2015.09.007

Clark, T. A., and Mackie, K. L. (2007). "Steam explosion of the softwood Pinus radiata with sulphur dioxide addition. I. Process optimisation," Journal of Wood Chemistry and Technology 7(3), 373-403. DOI: 10.1080/02773818708085275

Deublein, D., and Steinhauser, A. (2011). Biogas from Waste and Renewable Resources: An Introduction, $2^{\text {nd }}$ Ed., Wiley-VCH Verlag GmbH \& Co. KGaA, Weinheim, Germany.

Hansen, K. M. S., Zortea, R., Piketty, A., Vega, S. R., and Andersen, H. R. (2013). "Photolytic removal of DBPs by medium pressure UV in swimming pool water," Science of The Total Environment 443, 850-856. DOI: 10.1016/j.scitotenv.2012.11.064

Hoffmann, M. R., Martin, S. T., Choi, W., and Bahnemannt, D. W. (1995). "Environmental applications of semiconductor photocatalysis," Chemical Reviews 95(1), 69-96. DOI: 10.1021/cr00033a004

Kang, H. K., and Kim, D. (2012). "Efficient bioconversion of rice straw to ethanol with $\mathrm{TiO}_{2} / \mathrm{UV}$ pretreatment," Bioprocess and Biosystems Engineering 35(1-2), 43-48. DOI: $10.1007 / \mathrm{s} 00449-011-0589-9$

Kazuhito, H., Hiroshi, I., and Akira, F. (2005). " $\mathrm{TiO}_{2}$ photocatalysis: A historical overview and future prospects," Japanese Journal of Applied Physics 44(12), 82698285. DOI: $10.1143 / J J A P .44 .8269$

Kugelman, I. J., and McCarty, P. L. (1965) "Cation toxicity and stimulation in anaerobic waste treatment," Journal Water Pollution Control Federation 37(1), 97-116. DOI: org/10.1016/0043-1354(79)90043-5

Kougias, P. G., Boe, K., Tsapekos, P., and Angelidaki, I. (2014). "Foam suppression in overloaded manure-based biogas reactors using antifoaming agents," Bioresource Technology 153, 198-205. DOI: 10.1016/j.biortech.2013.11.083

Ksibi, M. (2003). "Photodegradation of lignin from black liquor using a UV/ $\mathrm{TiO}_{2}$ system," Journal of Photochemistry and Photobiology A: Chemistry 154(2-3), 211218. DOI: 10.1016/S1010-6030(02)00316-7

Kumar, S. G., and Devi, L. G. (2011). "Review on modified $\mathrm{TiO}_{2}$ photocatalysis under UV/visible light: Selected results and related mechanisms on interfacial charge carrier transfer dynamics," The Journal of Physical Chemistry A 115(46), 13211-13241. DOI: $10.1021 / \mathrm{jp} 204364 \mathrm{a}$

Kumari, D., and Singh, R. (2018). "Pretreatment of lignocellulosic wastes for biofuel production: A critical review," Renew. Sustain. Energy Rev. 90, 877-891. DOI: 10.1016/j.rser.2018.03.111

Lacombe, S., and Keller, N. (2012). "Photocatalysis: Fundamentals and applications in JEP 2011," Environmental Science and Pollution Research 19(9), 3651-3654. DOI: 10.1007/s11356-012-1040-8

Li, S. H., Liu, S., Colmenares, J. C., and Xu, Y. J. (2016). "A sustainable approach for lignin valorization by heterogeneous photocatalysis," Green Chemistry 18(3), 594607. DOI: $10.1039 / \mathrm{c} 5 \mathrm{gc} 02109 \mathrm{j}$ 
Liu, C., Shi, W., Li, H., Lei, Z., He, L., and Zhang, Z. (2014). "Improvement of methane production from waste activated sludge by on-site photocatalytic pretreatment in a photocatalytic anaerobic fermenter," Bioresource Technology 155, 198-203. DOI: 10.1016/j.biortech.2013.12.041

Ma, Y. S., Chang, C. N., Chiang, Y. P., Sung, H. F., and Chao, A. C. (2008). "Photocatalytic degradation of lignin using $\mathrm{Pt} / \mathrm{TiO}_{2}$ as the catalyst," Chemosphere 71(5), 998-1004. DOI: 10.1016/j.chemosphere.2007.10.061

Nations, S., Wages, M., Cañas, J. E., Maul, J., Theodorakis, C., and Cobb, G. P. (2011). "Acute effects of $\mathrm{Fe}_{2} \mathrm{O}_{3}, \mathrm{TiO}_{2}, \mathrm{ZnO}$ and $\mathrm{CuO}$ nanomaterials on Xenopus laevis," Chemosphere 83(8), 1053-1061. DOI: 10.1016/j.chemosphere.2011.01.061

Portjanskaja, E., Preis, S., and Kallas, J. (2006). "Aqueous photocatalytic oxidation of lignin and humic acids with supported $\mathrm{TiO}_{2}$," International Journal of Photoenergy 2006, Article ID 85927. DOI: 10.1155/IJP/2006/85927

Rawalekar, S., and Mokari, T. (2013). "Rational design of hybrid nanostructures for advanced photocatalysis," Advanced Energy Materials 3(1), 12-27. DOI: 10.1002/aenm.201200511

Sainsbury, P. D., Hardiman, E. M., Ahmad, M., Otani, H., Seghezzi, N., Eltis, L. D., and Bugg, T. D. (2013). "Breaking down lignin to high-value chemicals: The conversion of lignocellulose to vanillin in a gene deletion mutant of Rhodococcus jostii RHA1," ACS Chemical Biology 8(10), 2151-2156. DOI: 10.1021/cb400505a

Sinha, A. K., Sharma, U. K., and Sharma, N. (2008). "A comprehensive review on vanilla flavor: extraction, isolation and quantification of vanillin and other constituents," International Journal of Food Sciences and Nutrition 59(4), 299-326. DOI: 10.1080/09687630701539350

Sluiter, A., Hames, B., Ruiz, R., Scarlata, C., Sluitter, J., Templeton, D., and Crocker, D. (2011). Determination of Structural Carbohydrates and Lignin in Biomass (NREL/TP-510-42618), National Renewable Energy Laboratory, Golden, CO, USA.

Wong, R. J., Scott, J., Low, G. K. C., Feng, H., Du, Y., Hart, J. N., and Amal, R. (2016). "Investigating the effect of UV light pre-treatment on the oxygen activation capacity of $\mathrm{Au} / \mathrm{TiO}_{2}$," Catalysis Science \& Technology 6(23), 8188-8199. DOI: 10.1039/c6cy01717g

Article submitted: July 25, 2019; Peer review completed: January 12, 2020; Revised version received: January 14, 2020; Accepted: January 15, 2020; Published: January 24, 2020.

DOI: $10.15376 /$ biores.15.1.1747-1762 